\title{
Fake Maps: How I Use Fantasy, Lies, and Misinformation to Understand Identity and Place
}

There were two maps that really influenced me as I was growing up in suburban Texas in the '80s. The first was a map of Middle Earth found in J. R. R. Tolkien's The Hobbit and the other was a map of the spice planet Arrakis from Frank Herbert's Dune. Around fifth grade, I began to emulate those maps by creating my own based on imagined planets and civilizations. They were crude drawings, made with a \#2 pencil on typing paper. And I made tons of them. I had a whole binder full of these drawings, with countries that had names like Sh'kr-which, in my head, was pronounced sha-keer. Maps, so often meant to represent reality, instead solidified worlds of fantasy and fiction.

Of course, I was not thinking critically about cartography in this way when I was in grade school, but those fantasy maps laid the foundation for me to explore mapping again in the late '90s. By that time, I was going to art school in New York. It was such a contrast to growing up in Texas: the culture was different, the food was different (I never understood whole black beans in a burrito, coming from a place where refried beans were the norm), the ways people got around were different, and even the minorities were different. I was really out of my element, which I suppose is an important ingredient in an artist's development. Sometime halfway through college, nostalgia hit me very badly. I missed home, and drove back and forth between Houston and New York in between each semester. Every time I did, I would miss home even more. The only thing that sort of helped with homesickness was to look at a map of my hometown. Then this coping mechanism spilled into my art practice one night, when I drew a small map in my journal of a fictional city with the words Houston and New York in it, along with a number of other places that were important to me. Just like the penciled maps I made in the fifth grade, I made more and more of them, but this time with a more developed aesthetic language. I played around with text and colors, and experimented with different media. It wasn't long until I made the decision to start a long-term series based on this direction, which lasted for the next ten years: the America Series. \section{(1)}

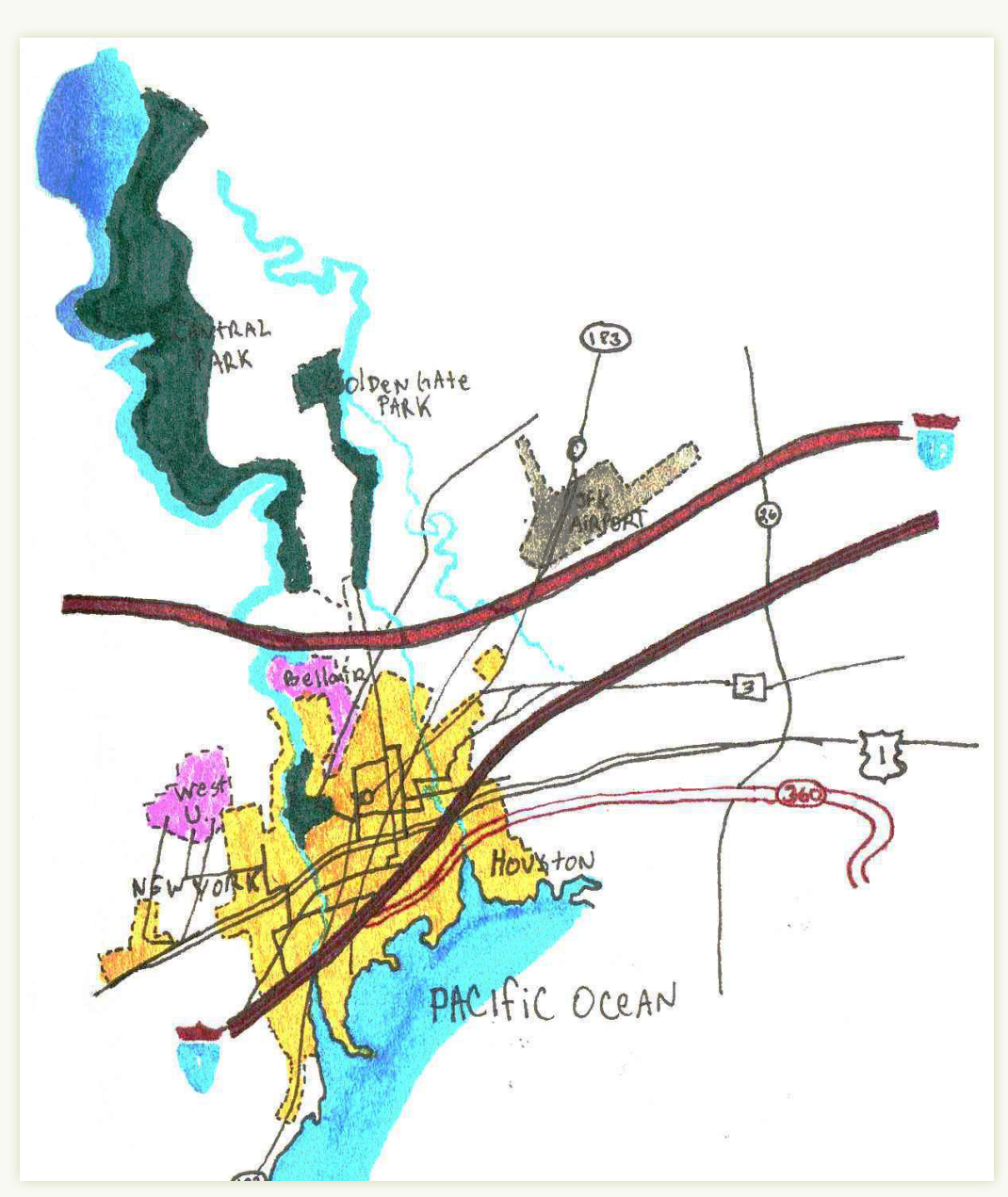

New York-Houston journal drawing, around 1995. 


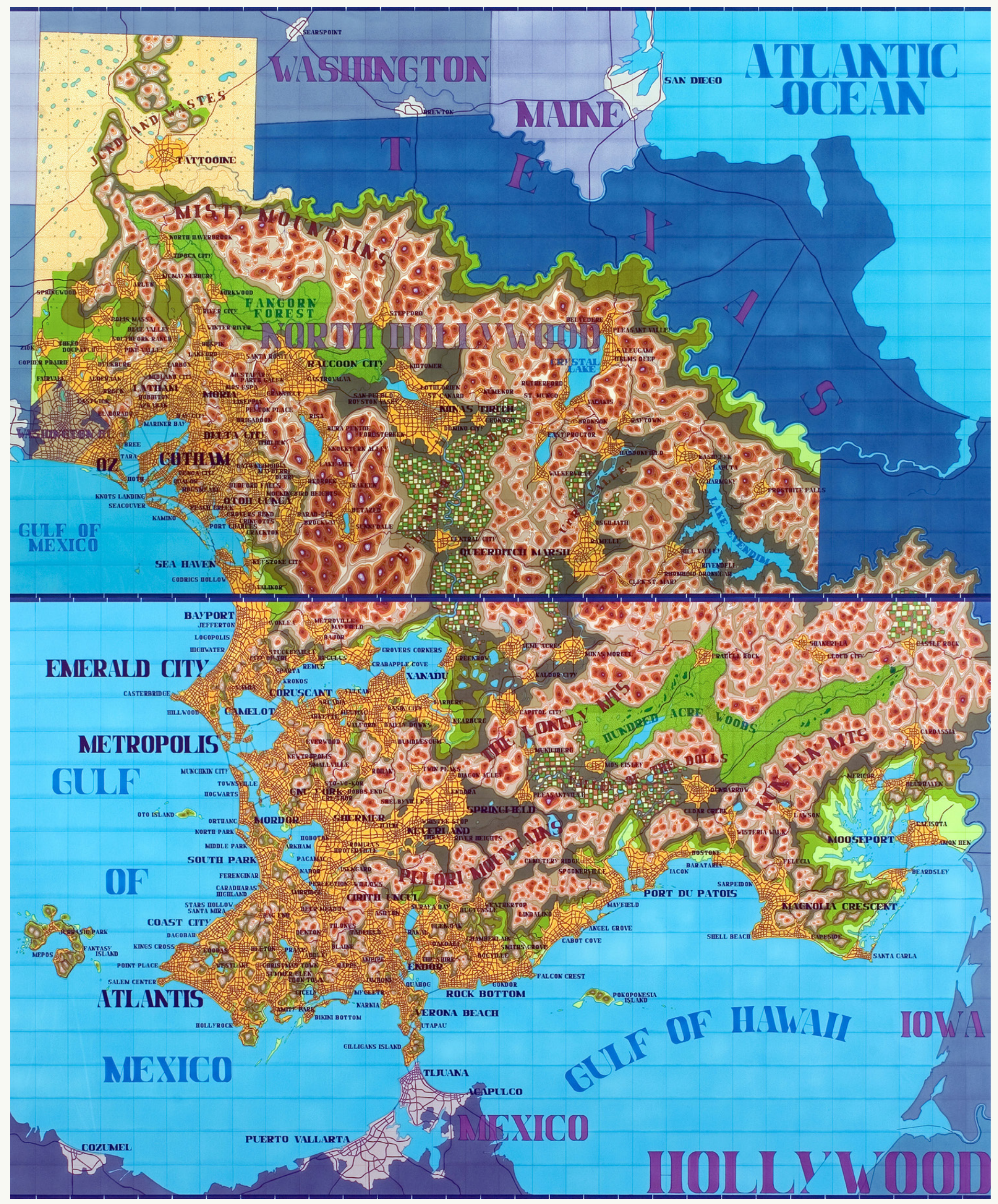

Hollywood. Ink on paper, 80" × 64". 2005. 
In the Philippines, where I was born but never lived, people talk about "going to America." Not to the United States of America, but just America. America-the idea, the stereotype, and the cultural identity - this was the metaphorical place immigrants really wanted to move to. Not Sugar Land, Texas, the suburb of Houston where my family ended up. With the America Series, I sought to appropriate the visual language of maps without being bounded by geographical rules, leaving the content to be anything I wanted. Using the name "America" directed the intention of the series towards more of an identity rather than a location. This series became a map of America based on my own history, interaction, and memory of this country and the culture. There were some "American" traits I made sure to have just to keep the map reminiscent of the real world; for example I had to include a region similar to the Great Lakes, along with an East and a West Coast, some sort of Canada to the north and Mexico to the south, a Gulf region, some kind of island state analogous to Hawaii, and around 50 states. All of this created the signature look of the US, except that my America included five extra states for a total number of 55 . This was an homage to the car, since the kind of map I originally appropriated was the road map and the national speed limit was 55-the double nickels. These five extra states were mostly there to add a more focused commentary on the culture and history of America. They are Hollywood (all the names in the state are fictional places in movies, books, and television), Monopoly (all the Fortune 500 headquarters are there; the capital of Monopoly is Bentonville, the HQ of Walmart), Disney (a company that definitely runs like a sovereign entity), Internet (the first version of the map was made in 2004 and the second in 2009; you can really see how much became outdated in those five years), and Territory (with the names of places that the US has occupied or colonized, including the Philippines). The last drawing in this series is the America key map. As I was drawing this final piece, nostalgia bubbled again, conjuring memories of the times I had worked on each individual state in the series: what I was thinking about then, or what I was listening to, or whom I had a crush on. So I chose a color scheme based on an old wooden map puzzle I had as a kid that had these same five colors.

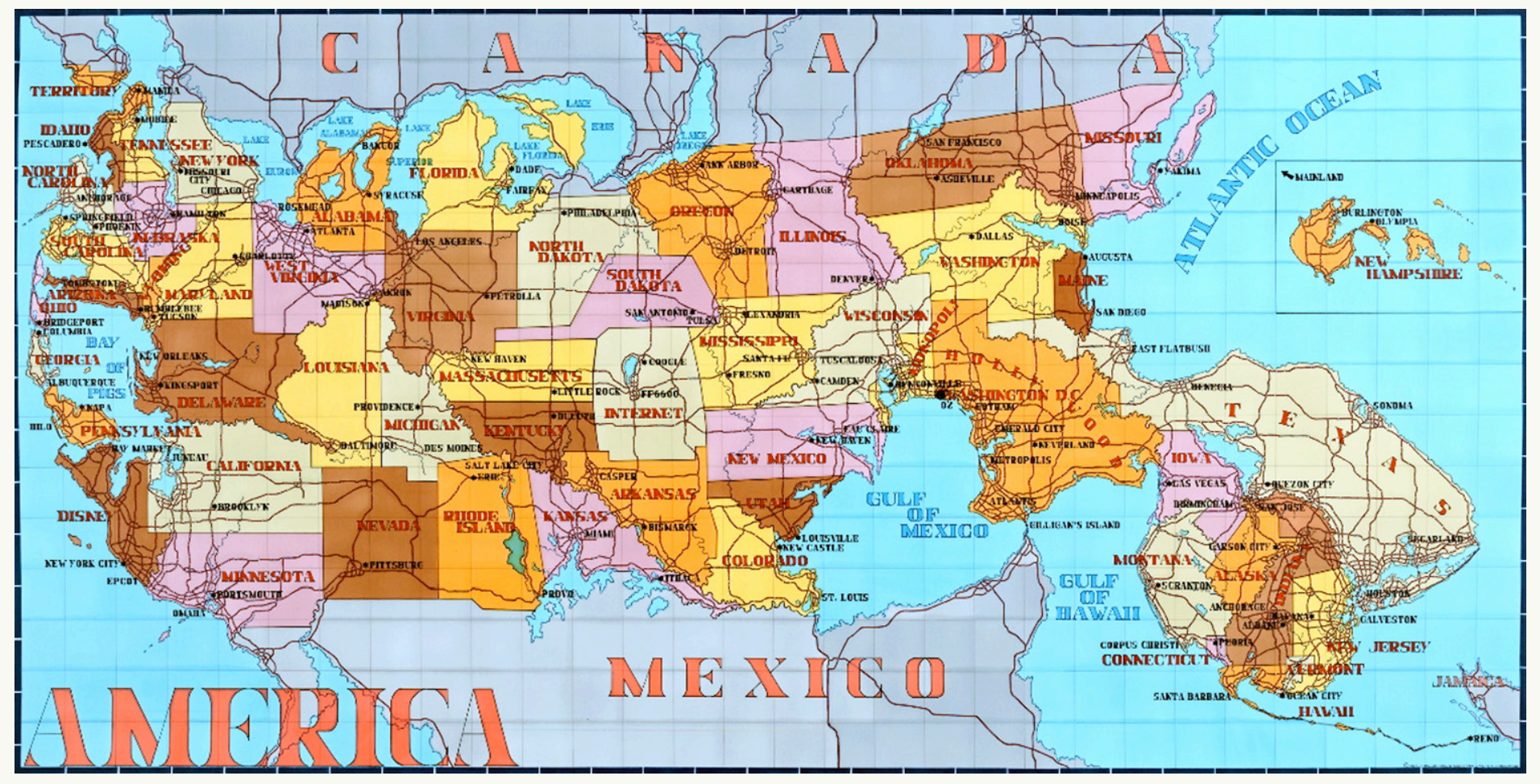

America (Key Map of the States and their Capitals). Ink on paper, 34" x 64". 2008. 
After the America series, I moved on to playing more with cartographic language and what it can do. My idea with the Strangerhood series was to use some of the conceptual strategies from the America series, but rather than look critically at the construction of my own identity, I wanted to see if I could look at the construction of a place's identity. The title Strangerhood is derived from sociologist Zygmunt Bauman (1991) and his allegorical use of the "stranger": an outside force that has both positive and negative effects on a society (and, in turn, a place). This was a role I was already familiar with since my childhood as a first-generation immigrant. This series took six neighborhoods in San Francisco that have been, or are being, gentrified: The Mission, Fisherman's Wharf, North Beach, The Castro, Chinatown, and Haight-Ashbury. I find that gentrification is part of a longer process that involves the appropriation of an identity or culture. To begin the series, I had to figure out how each neighborhood's identity

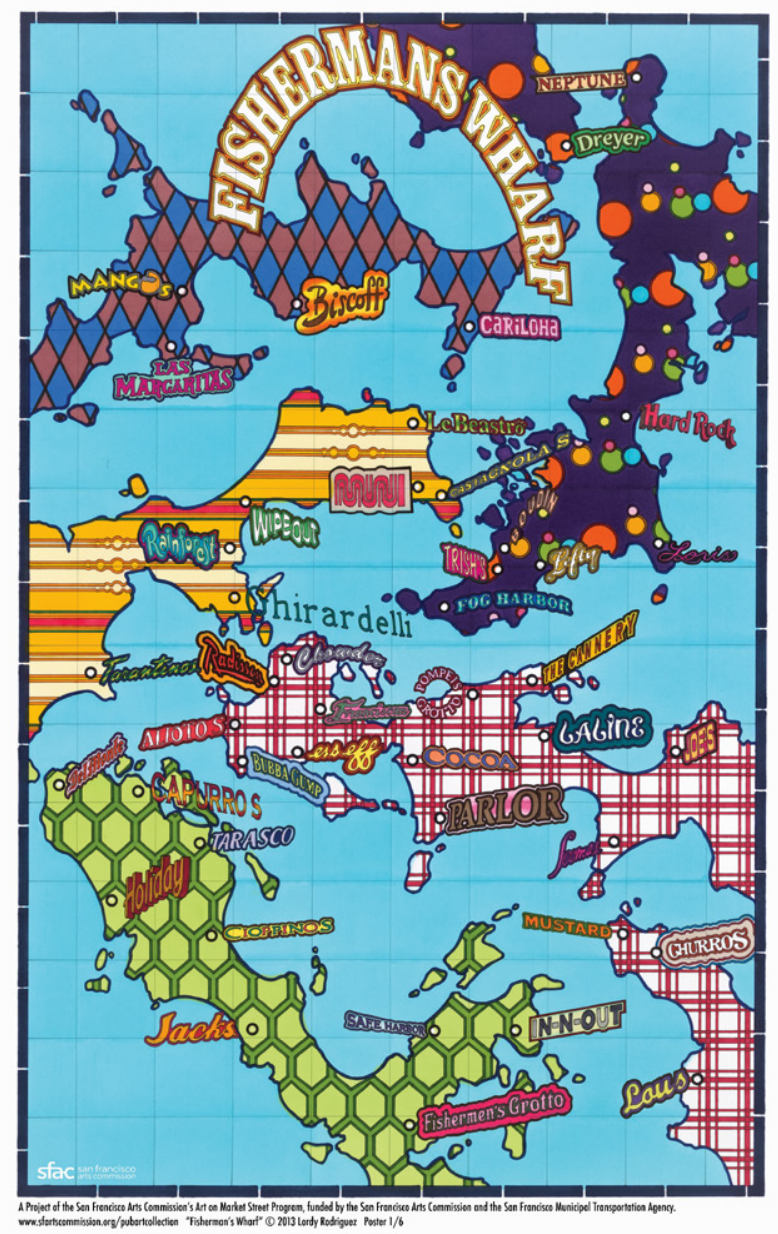

Fisherman's Wharf. Ink on paper, 32" × 21". 2014. and culture was demonstrated, exploited, and/or shared. I visited each one and looked for the visual languages that dressed them. For example, Fisherman's Wharf was originally a locale where Chinese and Italian immigrants sold their catches to a growing gold rush population, and it's become a popular tourist destination filled with what you would expect a tourist destination to have, things like souvenir shops and specialty foods. In each neighborhood I embodied the role of the stranger, taking pictures of all the patterns, color schemes, and texts found in the local businesses, architecture, murals, graffiti, etc. From these photos, I appropriated various patterns that made their way onto my map of Fisherman's Wharf. The origins of the patterns range from the San Francisco Carousel on Pier 39, to the Musée Mécanique (which is itself a transplanted identity from a totally different part of town), Ghirardelli Square, and the famous clam chowder bowls that are usually served in those red and white paper food

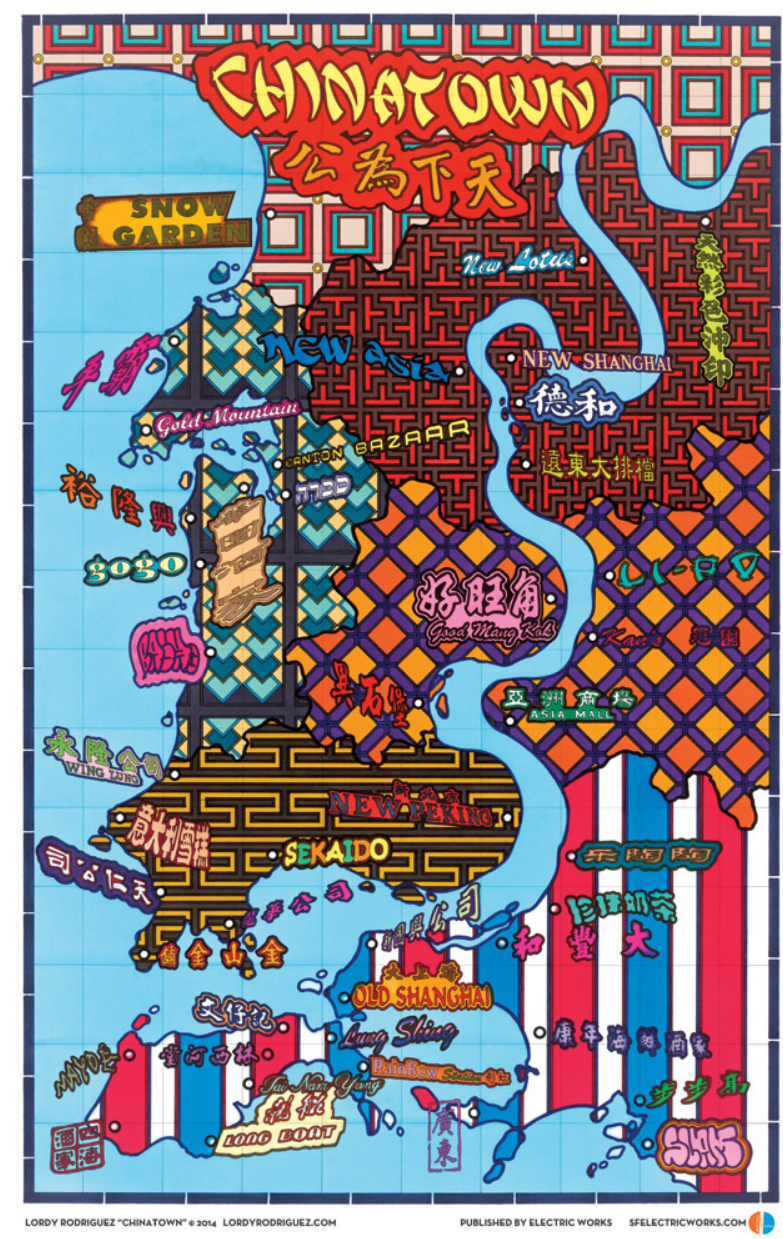

Chinatown. Ink on paper, 32" × 21". 2014 
baskets, often synonymous with a variety of tourist foods. There are hints of the Wharf's immigrant past, with some of the text marking the occasional Italian seafood restaurant. The text on these maps all comes from my photosincluding perspective distortion-with only the color schemes changed. This appropriated text then takes on the role of cities on the map. So, with city names such as "Rain Forest," "Hard Rock," or "In-N-Out," it's an easy jump to assume that this "place" is geared toward the tourist, for whom homogeneous commercial establishments are the norm, rather than the more culturally specific immigrant neighborhood and identities.

A permanent installation of the series is located at San Francisco International Airport, in Terminal 3.

\section{WHERE I AM NOW}

My FIRST OFFICIAL art piece that made use of maps was in 1996. Since then, I've tried to stretch the visual language of maps with different strategies and different content. Some series were purely abstract with no text, while others were heavy with recognizable references and strong social commentaries. One series attempted to compare the visual language of maps with other visual languages as a way to expose a universal structure, similar to Chomsky's (1965) idea of Universal Grammar for linguistics. And just like Universal Grammar, that series was inconclusive. I

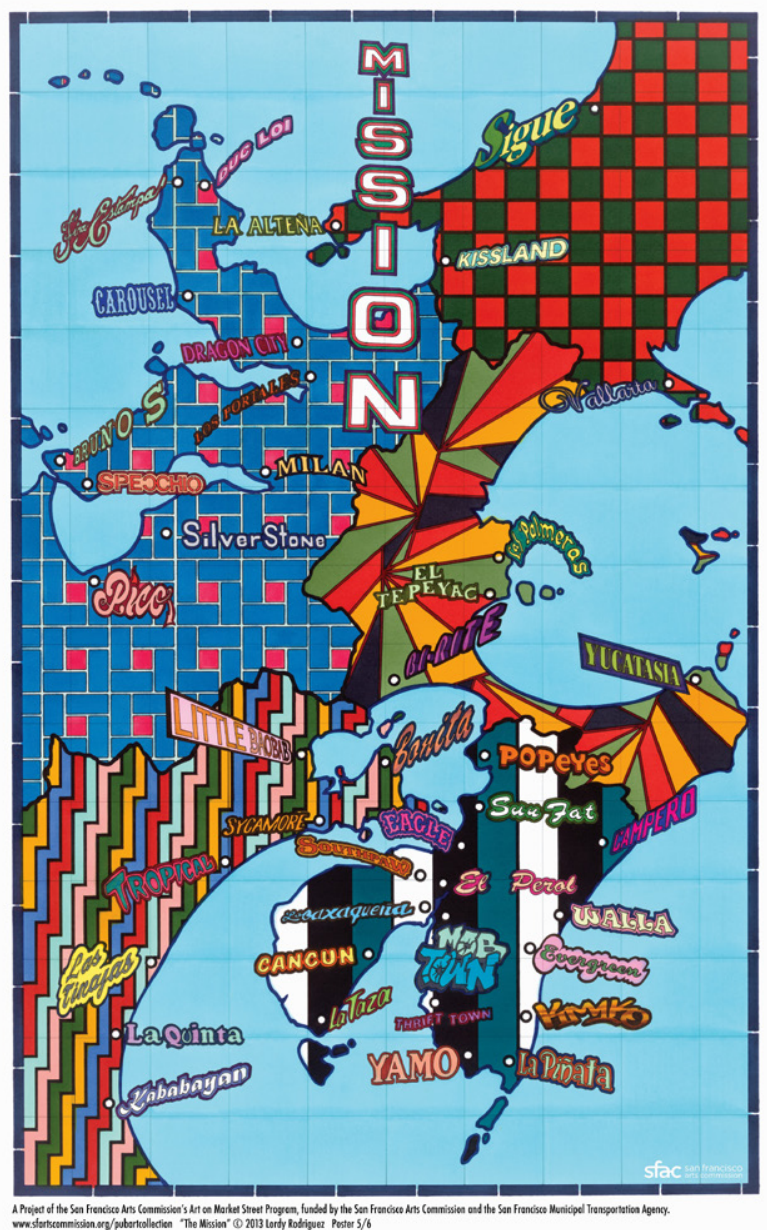

The Mission. Ink on paper, 32" × 21". 2014

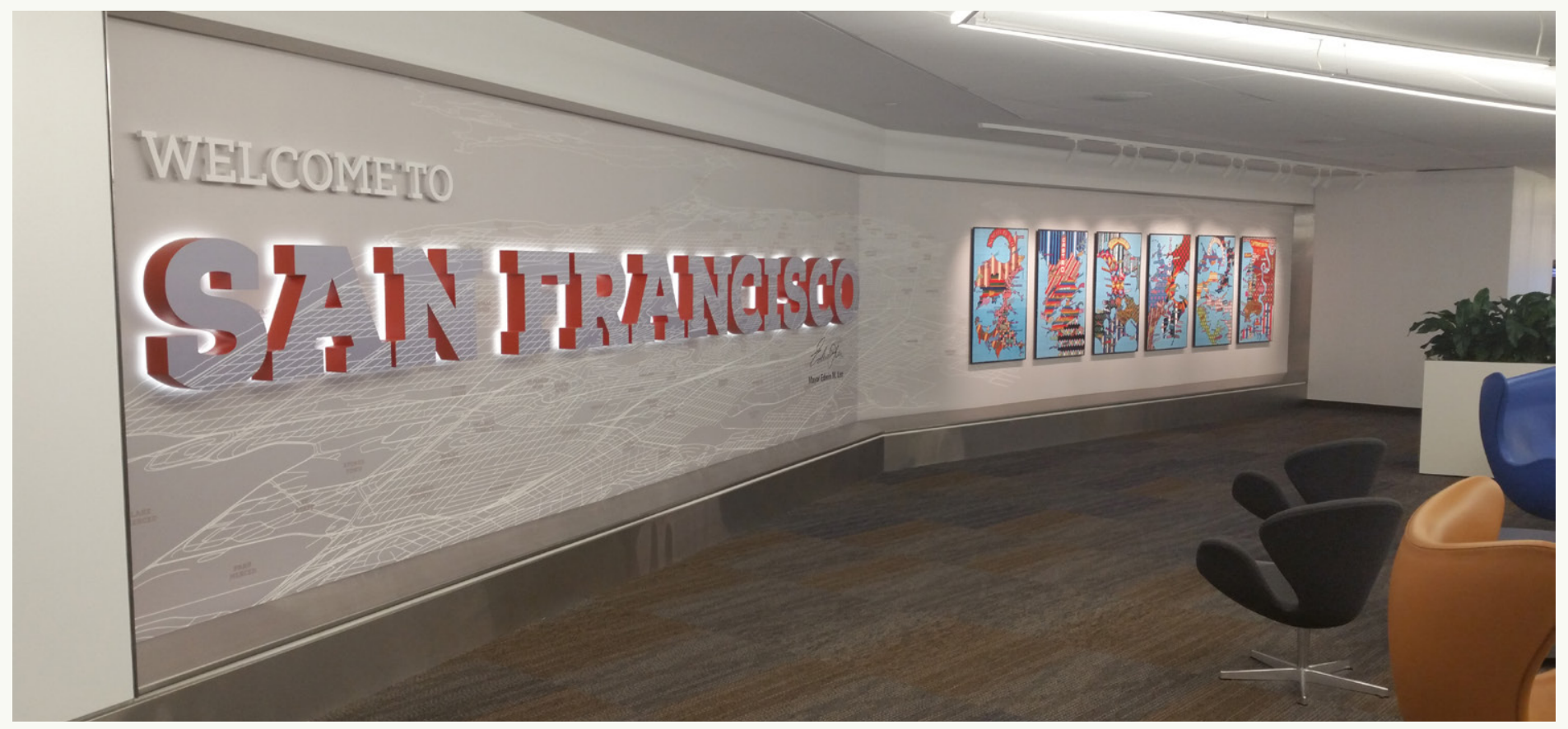



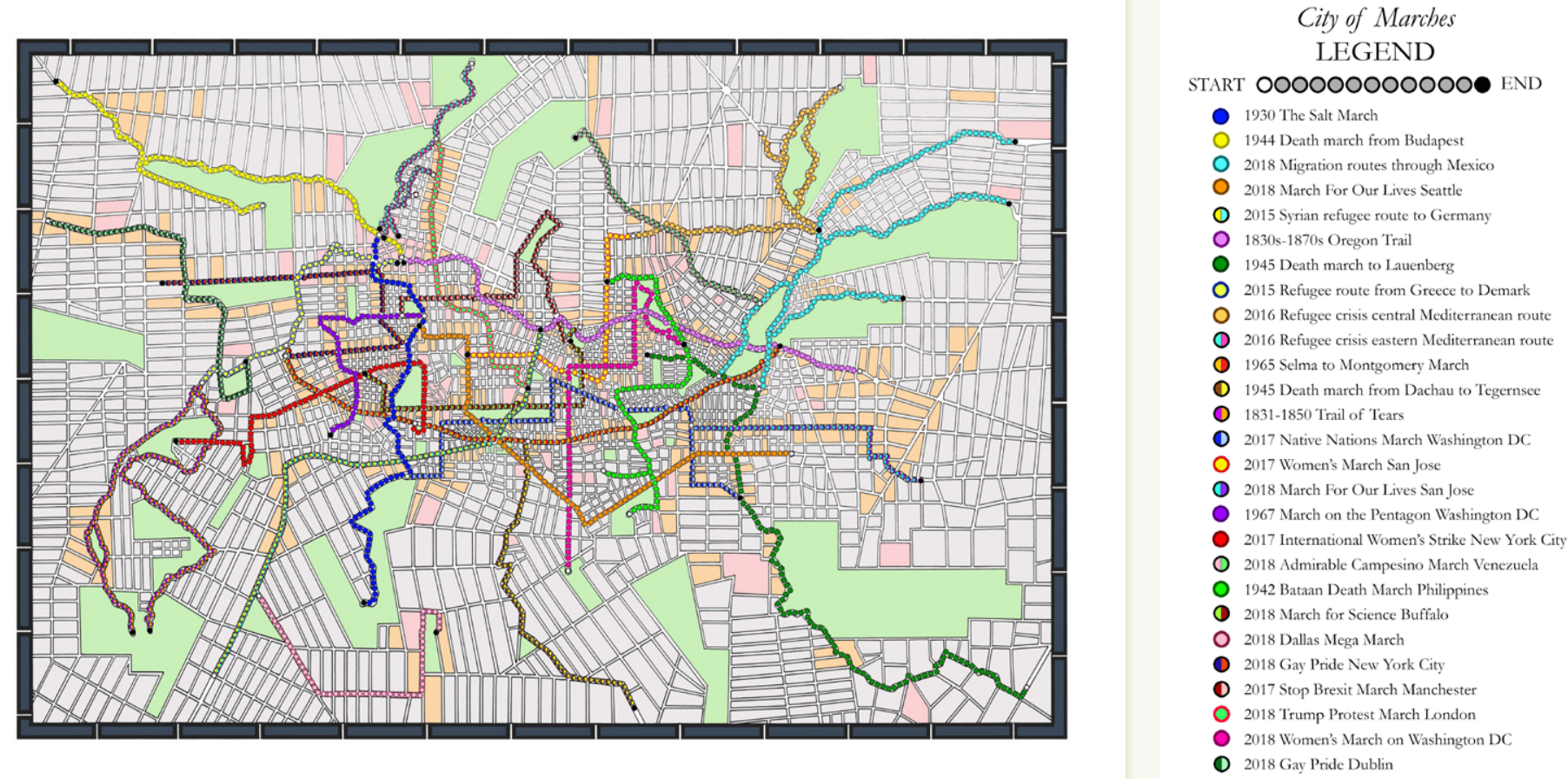

Left: City of Marches. Dye-infused aluminum, 28" × 40". 2018. Right: City of Marches legend.

felt that art shouldn't have conclusions, so I was OK with where it took me. But since Trump was elected, the world seems different, along with the American identity that I knew. I can't continue abstractly working with visual languages in a way that is divorced from what is going on in this country and the world. There isn't anything new with this administration that we haven't seen before: my parents knew and experienced the effects of Marcos and martial law in the Philippines a few years before I was born. But while my generation's response to the administration likewise isn't new-Boomers protested against the Vietnam War and embarked on myriad social and cultural movements- the sheer number of protesters and protests is. The scale is owed to the wholly unique organizing power of the current generation. So, when I was approached by the San Jose Museum of Art for a commissioned piece to be included in a show about walking in 2017, I started with researching protest marches. The result was a piece called "City of Marches," in which I took 27 marches, protests, parades, and famous trails out of their original context and superimposed all of them on top of each other within a fictional city grid. The urban planning of this "city" is molded by the marches and protests, a departure from the normative protest, where the route is molded by the shape of the city. The cultural impacts of these walks are forever commemorated by the street blocks that are shaped by them. I'm fascinated with my generation's response to what feels like an attack on our foundation as a people and culture. As more protests and marches occur in our daily lives, I'm hoping to be there to record them in a new map with a new city and a renewed sense of communal solidarity, only this time my work won't be all fiction.

\section{REFERENCES}

Bauman, Zygmunt. 1991. Modernity and Ambivalence. Ithaca, NY: Cornell University Press.
Chomsky, Noam. 1965. Aspects of the Theory of Syntax. Cambridge, MA: MIT Press. 